\title{
Lipids Shed into the Culture Medium by Trypomastigotes of Trypanosoma cruzi
}

\author{
Rosalia Agusti, Alicia S Couto, Maria Júlia M Alves*, Walter Colli*/+, \\ Rosa M de Lederkremer
}

\begin{abstract}
Cihidecar, Departamento de Química Orgánica, Facultad de Ciencias Exactas y Naturales, Universidad de Buenos Aires, 1428, Buenos Aires, Argentina *Departamento de Bioquímica, Instituto de Química, Universidade de São Paulo, Caixa Postal 26077, 05599-970 São Paulo, SP, Brasil

Trypomastigote forms of Trypanosoma cruzi were metabolically labeled with $\left[{ }^{14} \mathrm{C}\right]$-ethanolamine and $\left[{ }^{3} \mathrm{H}\right]$-palmitic acid. Lipids shed to the culture medium were analyzed and compared with the parasite components. Phosphatidylcholine and lysophosphatidylcholine accounted for $53 \%$ of the total incorporated precursor. Interestingly, phosphatidylethanolamine and its lyso derivative lysophosphatidylethanolamine, although present in significant amounts in the parasites, could not be detected in the shed material. Shed lipids were highly enriched in the desaturated fatty acids $C_{16: 1}$ and $C_{18: 1}$ when compared to the total fatty acid pool isolated from the parasites.
\end{abstract}

Key words: $\left[{ }^{14} \mathrm{C}\right]$-ethanolamine and $\left[{ }^{3} \mathrm{H}\right]$-palmitic acid incorporation - phospholipids - desaturated fatty acids

Lipidic components and their derivatives have been lately related to important biological functions in different systems. In this respect there is an increasing interest in the study of lipids from trypanosomatids as chemotaxonomic and/or chemoterapeutic targets (Docampo \& Pignataro 1991, Machado de Domenech et al. 1992, Schneider et al. 1994, Racagni et al. 1995).

Some years ago, we began a systematic study of the lipids of the trypomastigote stage. We have already characterized neutral and zwitterionic lipids (Uhrig et al. 1997) and inositolphospholipids (Uhrig et al. 1996), among others (Couto et al. 1985, Uhrig et al. 1992). The shedding of different lipidic components in vesicles has been reported (Gonçalves et al. 1991). Qualitative and quantitative differences between the shed components and the lipids remaining in the parasite were observed (Couto et al. 1991).

This investigation received financial support from Consejo Nacional de Investigaciones Científicas y Técnicas (Conicet) and Universidad de Buenos Aires to RM de Lederkremer, Fundação de Amparo à Pesquisa do Estado de São Paulo (Fapesp, thematic project 95/4562-3) and Conselho Nacional de Desenvolvimento Científico e Tecnológico (CNPq) to W Colli and MJM Alves. RML and ASC are research members of Conicet.

${ }^{+}$Corresponding author. Fax: +55-11-815-5579. E-mail: walcolli@usp.br

Received 26 April 1999

Accepted 9 September 1999
The characterization of shed components may help to explain the multiple manifestations of the disease, including autoimmune processes. In this work, we describe neutral and zwiterionic lipids shed to the culture medium. Metabolic incorporation of $\left[{ }^{14} \mathrm{C}\right]$-ethanolamine and $\left[9,10(\mathrm{n})-{ }^{3} \mathrm{H}\right]$-palmitic acid were used as tracers in order to compare the labeled lipids with the parasite composition.

\section{MATERIALS AND METHODS}

Parasites - Trypomastigotes of T. cruzi (Y strain) were obtained from infected LLC-MK ${ }_{2}$ epithelial cell monolayers maintained in Dulbecco's modified Eagle medium (DME) containing 2\% fetal calf serum (FCS). Parasites were collected on the fifth day after infection (Andrews \& Colli 1982).

Parasite labeling - Parasites $\left(1.5 \times 10^{9}\right)$ were resuspended at a density of $8 \times 10^{7}$ cells $/ \mathrm{ml}$ in DME containing $2 \%$ of fetal calf serum, $20 \mathrm{mM}$ Hepes and metabolically labeled with $\left[9,10(\mathrm{n})-{ }^{3} \mathrm{H}\right]$-palmitic acid (Amersham, Buckinghamshire, England, 54 $\mathrm{Ci} / \mathrm{mmol}, 41 \mathrm{mCi} / \mathrm{ml}$ ) for 2,4 and $6 \mathrm{~h}$ at $37^{\circ} \mathrm{C}$. The homogeneity of palmitic acid was tested before the labeling experiment by RPTLC. Incorporation of $\left[1,2-{ }^{14} \mathrm{C}\right]$-ethanolamine (NEN, Boston, USA, $3 \mathrm{mCi} /$ mmol) was performed with $1 \times 10^{9}$ trypomastigotes. Parasites were resuspended at a density of $10 \times 10^{7}$ cells $/ \mathrm{ml}$ in DME, $2 \% \mathrm{FCS}, 20 \mathrm{mM}$ Hepes, and were incubated with $\left[1,2-{ }^{14} \mathrm{C}\right]$-ethanolamine, $5 \mathrm{mCi} / \mathrm{ml}$, for $6 \mathrm{~h}$ at $37^{\circ} \mathrm{C}$.

After incubation, microscopic observation showed that all parasites remained viable. Trypomastigotes were harvested and the culture 
medium was filtered through Millipore $(0.22 \mu \mathrm{m})$ and freeze-dried.

Lipid extraction - Parasites and the corresponding dried medium were twice extracted with chloroform:methanol 2:1 and 1:1 (v/v). The extracts were separated by centrifugation, pooled, dried in vacuo and fractionated on DEAE-Sephadex A25 (acetate form, $10 \times 0.5 \mathrm{~cm}$ ) as previously described (Couto et al. 1991). Lipids that do not interact with the resin were eluted with chloroform:methanol:water (15:30:4, $100 \mathrm{ml})$, and strongly acidic lipids were eluted with chloroform:methanol $: 0.8 \mathrm{M}$ sodium acetate $(15: 30: 4,100 \mathrm{ml})$. Non-bound lipids labeled with $\left[{ }^{14} \mathrm{C}\right]$-ethanolamine were resuspended in water and passed through a $\mathrm{C}_{18}$-clean up cartridge (Worldwide monitoring PA, USA). Salts and free radioactive precursor were eluted with water and lipids were recovered with methanol.

As a control, a sample of the $\left[{ }^{3} \mathrm{H}\right]$-palmitic acid labeled extract obtained from the parasites was incubated for $6 \mathrm{~h}$ in DME containing $2 \%$ of FCS, 20 $\mathrm{mM}$ Hepes. The mixture was extracted and fractionated as above.

TLC and fluorography - Phospholipids and lipid standards were purchased from Sigma. Thin layer chromatography (TLC) was performed on silica gel 60 precoated plates (Merck) using the following solvent systems: A) chloroform:methanol: water (65:25:4, by vol.); B) hexane:ethyl ether:acetic acid (70:35:1, by vol.); C) two-dimensional TLC was performed using chloroform:methanol:13.3M $\mathrm{NH}_{4} \mathrm{OH}(65: 25: 5$, by vol.) in the first direction and chloroform:acetone:methanol:acetic acid:water (30:40:10:10:1, by vol.) in the second direction. In this case, standard lipids were run in the same plate and located with iodine vapor; D) chloroform: methanol:2.5 $\mathrm{M} \mathrm{NH}_{4} \mathrm{OH}$ (60:40:9, by vol.)

Reverse-phase TLC was performed on RP-18 F254 precoated plates (Merck) using acetonitrile: acetic acid $(1: 1, \mathrm{v} / \mathrm{v})$ (solvent system $\mathrm{E})$.

In all cases, radioactive samples were located by fluorography at $-70^{\circ} \mathrm{C}$ using $\mathrm{EN}^{3} \mathrm{HANCE}$ (NEN) and Kodak-X-Omat AR films. Radioactivity was determined in a 1214 RackBeta Wallac liquid scintillation counter.

Analysis of fatty acids - Free fatty acids were extracted from the TLC plate with chloroform and the corresponding methyl esters were obtained by treatment with $\mathrm{BF}_{3} /$ methanol (20\% in methanol, Merck, $1 \mathrm{ml}$ ) at $80^{\circ} \mathrm{C}$ for $1 \mathrm{~h}$ in a screw cap test tube (Manku 1983). Labeled fatty acid methyl esters were analyzed by RP-TLC in solvent E.

Hydrogenation - Labeled fatty acid methyl esters were subjected to hydrogenation with palladium on activated carbon (palladium content $10 \%$, Aldrich), using an hydrogen pressure of $3 \mathrm{~atm}$. The reaction was performed for 4 to $5 \mathrm{~h}$ with shaking at room temperature (Kates 1986). A sample of linoleic acid methyl ester $\left(\mathrm{C}_{18: 2}\right)$ was treated under the same conditions as a reaction control.

Phosphatidylinositol phospholipase $C$ digestion - The acidic lipids were suspended in $0.5 \mathrm{ml}$ of $50 \mathrm{mM}$ Tris/HCl, $\mathrm{pH} 7.4$ and incubated for $90 \mathrm{~min}$ at $37^{\circ} \mathrm{C}$ with 0.1 units of phosphatidylinositol-phospholipase C (PI-PLC) from Bacillus thuringiensis in the presence of $0.1 \%$ deoxycolate (Menon 1994).

\section{RESULTS}

Trypomastigote forms of $T$. cruzi were metabolically labeled with $\left[{ }^{3} \mathrm{H}\right]$-palmitic acid. Preliminary trials have shown that different incorporation times resulted in the same lipid pattern. Thus, incorporation for $6 \mathrm{~h}$ was adopted throughout the experimental work in order to optimize incorporation of the label. The culture medium was separated by centrifugation, filtered by Millipore and freeze-dried. The material obtained was extracted with chloroform:methanol. The lipidic extract was fractionated on a DEAE-Sephadex ( $\mathrm{AcO}^{-}$form) column and the unbound fraction was analyzed by TLC and compared with a fraction obtained by the same procedure from labeled parasites (Fig. 1a). The total pattern of both fractions is significantly different, confirming that shed components do not originate from lysis of parasites. The addition of parasites freshly labeled extracts to the same medium used for the incorporation did not lead to the conversion of the pattern of Fig. 1 (lane 1) to that of lane 2, indicating that lipid modifications were not produced by any residual enzyme activity in FCS.

The culture medium of trypomastigote forms metabolically labeled with $\left[{ }^{14} \mathrm{C}\right]$-ethanolamine was also analyzed. No radioactive PE was detected and only a trace of labeled LPE was shown (Fig. 1b, lane 1). Shed ${ }^{3} \mathrm{H}$-palmitic acid labeled lipids were run in the same TLC only for comparison (Fig. 1b, lane 2). No PC could be detected when labeling with ethanolamine, as trypomastigotes do not biosynthesize this phospholipid by sequential methylation of PE (Uhrig et al. 1997) as is usual in other systems (Vance 1990).

Phosphatidylcholine (PC) and lysophosphatidylcholine (LPC) were detected in the shed lipids labeled with ${ }^{3} \mathrm{H}$-palmitic acid. As PC and lysophosphatidylethanolamine (LPE) overlap in the solvent used, two dimensional TLC in basic and acidic solvent systems was necessary to confirm their identity (Figs $2 \mathrm{a}, \mathrm{b})$. As expected, no radioactive phosphatidylethanolamine (PE) was detected, in spite of this phospholipid be a component of the parasite.

The fatty acids from PC were analyzed by RPTLC after methylation. Only the $\mathrm{C}_{16: 0}$ fatty acid was detected (not shown). The fast moving components in Fig. 1a, lane 2 were eluted from the TLC 

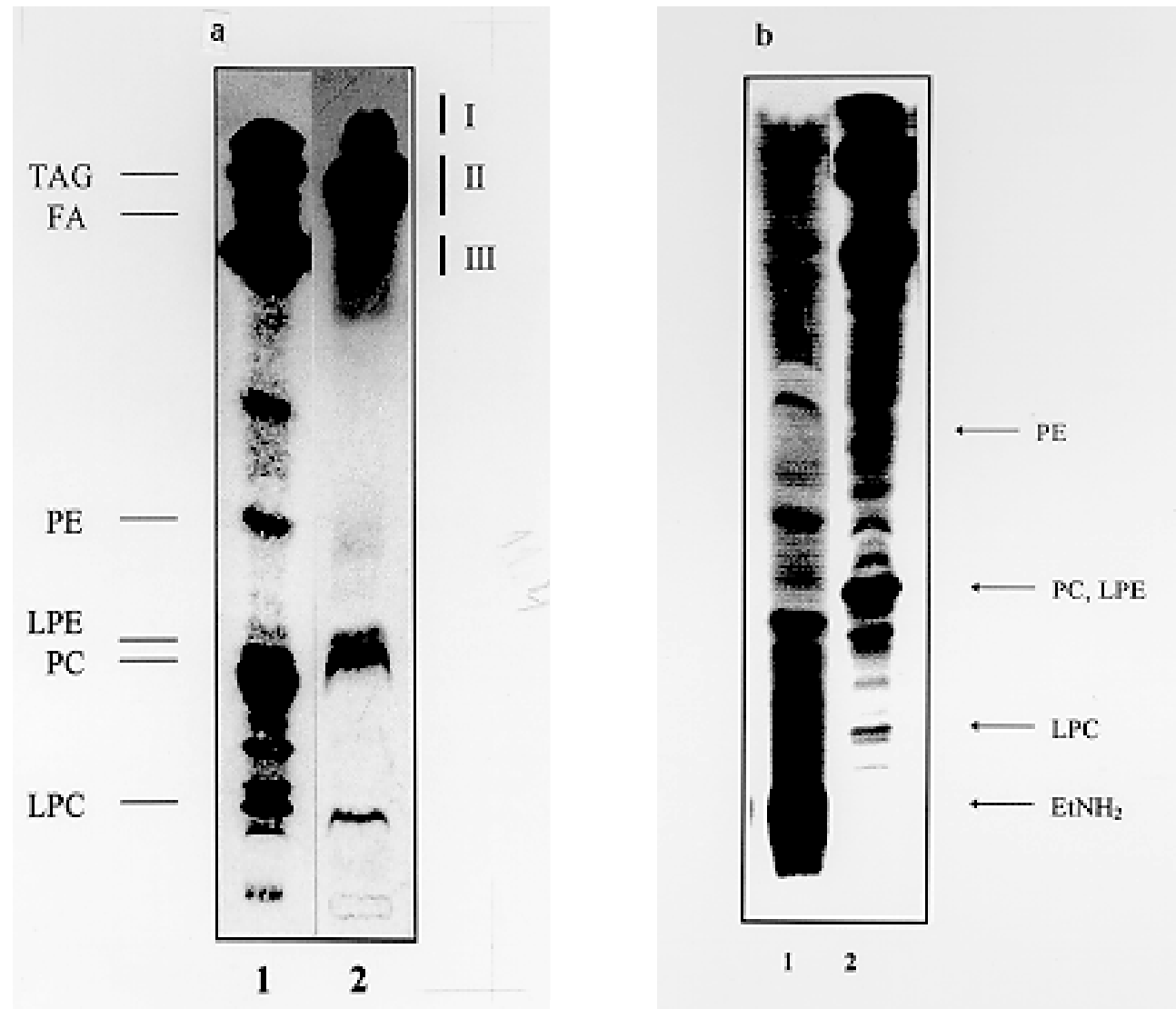

Fig. 1: fluorography of thin layer chromatography of non-bound lipids obtained from DEAE-Sephadex (AcO- form) chromatography. a: parasites metabolically labeled with $\left[{ }^{3} \mathrm{H}\right]$-palmitic acid; lane 1: trypomastigotes, lane 2: shed lipids; b: shed lipids obtained from parasites incorporated with lane $1,\left[{ }^{14} \mathrm{C}\right]$-ethanolamine, and lane $2,\left[{ }^{3} \mathrm{H}\right]$-palmitic acid. Migration of authentic standards are indicated by arrows with the following abbreviations: FA: fatty acids; LPC: lysophosphatidylcholine;LPE: lysophosphatidyl-ethanolamine; PC: phosphatidylcholine; PE: phosphatidylethanolamine; TAG: triacylglycerol.

in three fractions (I, II and III) and rechromatographed in solvent B (Fig. 3). As expected, no triacylglycerol (TAG) was detected confirming no lysis of parasites. All fractions contained free fatty acids, which were methylated and analyzed by RPTLC in comparison with the same sample subjected to hydrogenation (Fig. 4). Spots corresponding to $\mathrm{C}_{16: 0}, \mathrm{C}_{18: 0}, \mathrm{C}_{16: 1}$ and $\mathrm{C}_{18: 1}$ were detected. Unsaturated fatty acids disappeared by hydrogenation. The $\mathrm{C}_{16: 1}$ is the most abundant radioactive fatty acid. Of course, it must be appreciated that not all $\mathrm{C}_{16: 0}$ is of endogenous origin since some contamination with the original labeled precursor is unavoidable.

Acidic lipids recovered from the bound fraction of the ion-exchange chromatography were also analyzed by TLC in solvent D (not shown). Spots migrating as the reported inositolphospholipids (Uhrig et al. 1996) were found. As expected, all of them resulted sensitive to PI-PLC digestion.

\section{DISCUSSION}

In every stage of the T. cruzi cycle, the characterized antigenic structures present a lipidic moiety that anchors the protein to the membrane (Güther et al. 1992, Couto et al. 1993, Almeida et al. 1994, Acosta Serrano et al. 1995, Bertello et al. 1996, Ferguson 1997, Agusti et al. 1997) and antigens released by the parasites have been described as potential targets for immunoidentification (Dzbenski 1974, Araujo 1982, Petry \& Eisen 1989, Petry \& van Voorhis 1991, Corral et al. 1996).

Circulating antigens either free or in the form of immunocomplexes may play an important role in the immunopathology of Chagas disease, contributing to processes of autoaggression or immunosuppression (Petry \& Eisen 1989). The knowledge of the intimate mechanism of surface antigen shedding would contribute to the understanding of these phenomena. In this direction we have already described the shedding of lipidic components to the 

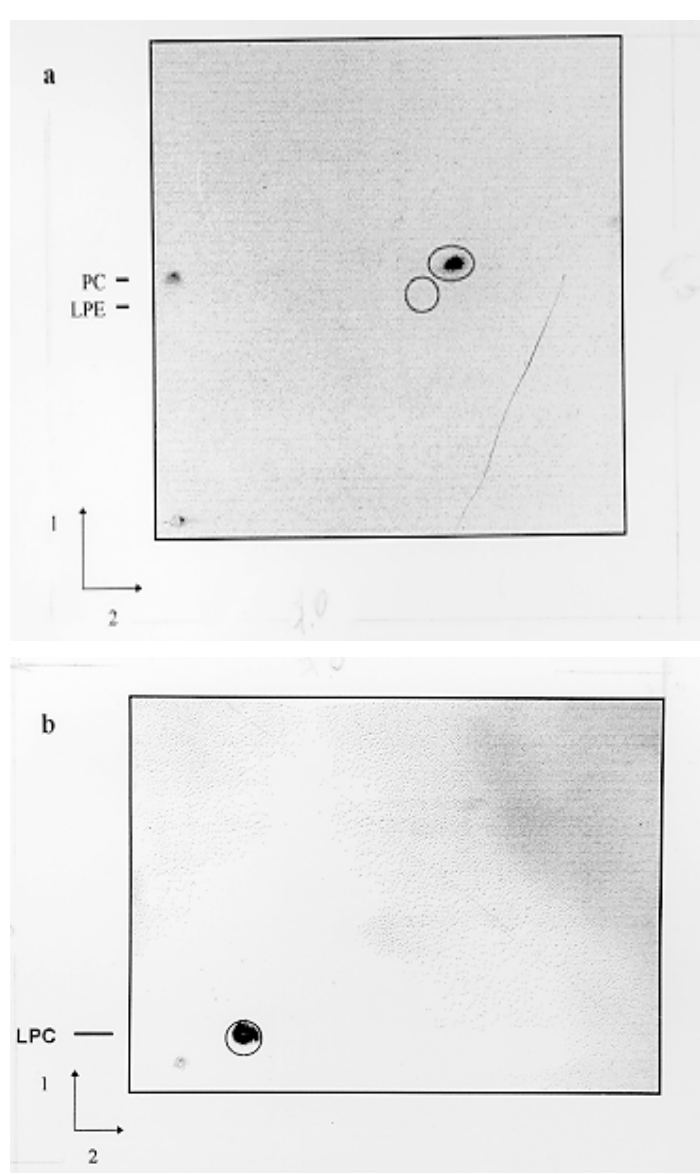

Fig. 2: two dimensional thin-layer chromatography of the shed compounds from Fig. 1a migrating as (a) PC, (b) LPC using chloroform:methanol:13.3 $\mathrm{M} \mathrm{NH}_{4} \mathrm{OH}(65: 25: 5)$ in the first direction and chloroform:acetone:methanol:acetic acid:water (30:40:10:10:1) in the second direction. Circles correspond to standards of phosphatidylcholine, lysophosphatydylcholine and lysophosphatidylethanolamine that were run in the same plate.

culture medium of the infective forms (Couto et al. 1991), supporting reports for the spontaneous release of antigens in vesicles (Gonçalves et al. 1991).

In the present work, we have found a low content of radioactive neutral lipids in the culture medium in contrast with the results obtained with induced vesiculation of epimastigote forms ( $\mathrm{Da}$ Silveira \& Colli 1981). Furthermore, PC and PE are the main components in epimastigote vesicles and the composition of lipids in trypomastigote forms is $3.1 \% \mathrm{PE}, 2.6 \% \mathrm{LPE}, 13.5 \% \mathrm{PC}$ and $5.1 \% \mathrm{LPC}$ (Uhrig et al. 1997). However, radioactive PE could not be detected in the shed fraction with neither of the precursors used.

It is well known that lipids and mainly phospholipids, regulate the membrane fluidity and prepare the bilayer for sheltering and maintenance of active membrane proteins (Singh et al. 1996). This

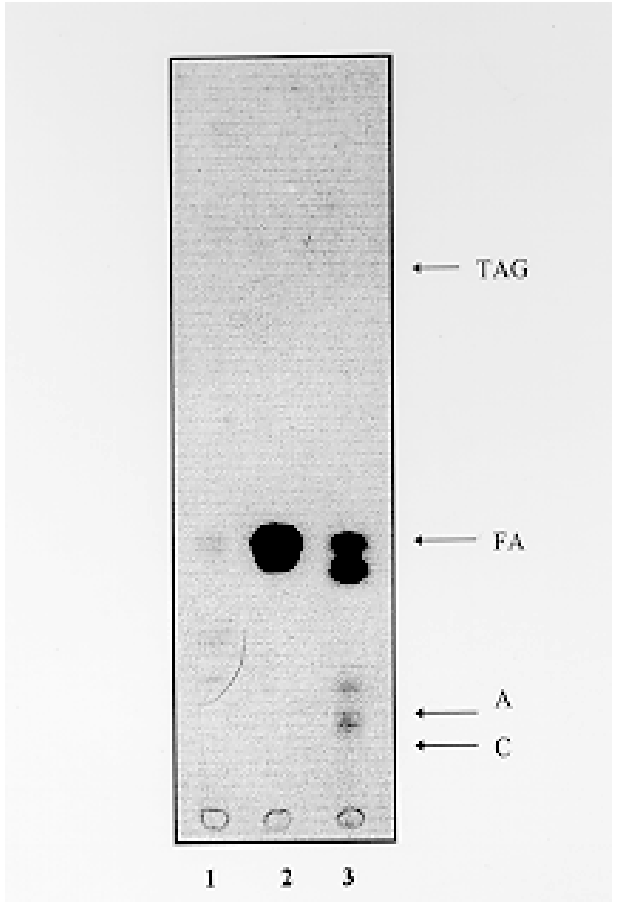

Fig.3: analysis by thin-layer chromatography and fluorography of fractions I (lane 1), II (lane 2) and III (lane 3) from Fig. 1a (lane 2) using hexane:ethyl ether:acetic acid (70:35:1) as solvent. FA: fatty acids; TAG: triacylglycerol; A: hexadecylglycerol; C: ceramide.

may be related to the shedding of various important proteins of the trypomastigote stage such as SAPA (Affranchino et al. 1989, Pollevick et al. 1991, Agusti et al. 1997) or Tc-85 (Couto et al. 1993, Abuin et al. 1996) both being anchored by a glycosylphosphatidylinositol (GPI) to the surface membrane. It has been speculated that GPI-anchored proteins partition preferentially in plasma membrane domains enriched in certain membrane constituents. The functional consequences of this association are not clear, but perhaps it is important in membrane remodelling events such as vesiculation and some forms of endocytosis (Whitlow et al. 1993). The fact that only certain lipid components of the parasite membrane, namely PC, LPC and free fatty acids, are present in the shed material would highlight the selectivity of this process.

The most striking finding was the presence of $\mathrm{C}_{16: 1}$ and $\mathrm{C}_{18: 1}$ free fatty acids in shed lipid fraction. Although unsaturated fatty acids have been detected free and as components of PC and TAG (Uhrig et al. 1997) when cold trypomastigotes were analysed (cf. also Kaneda et al. 1986, Leon et al. 1989, Esteves et al. 1989), 


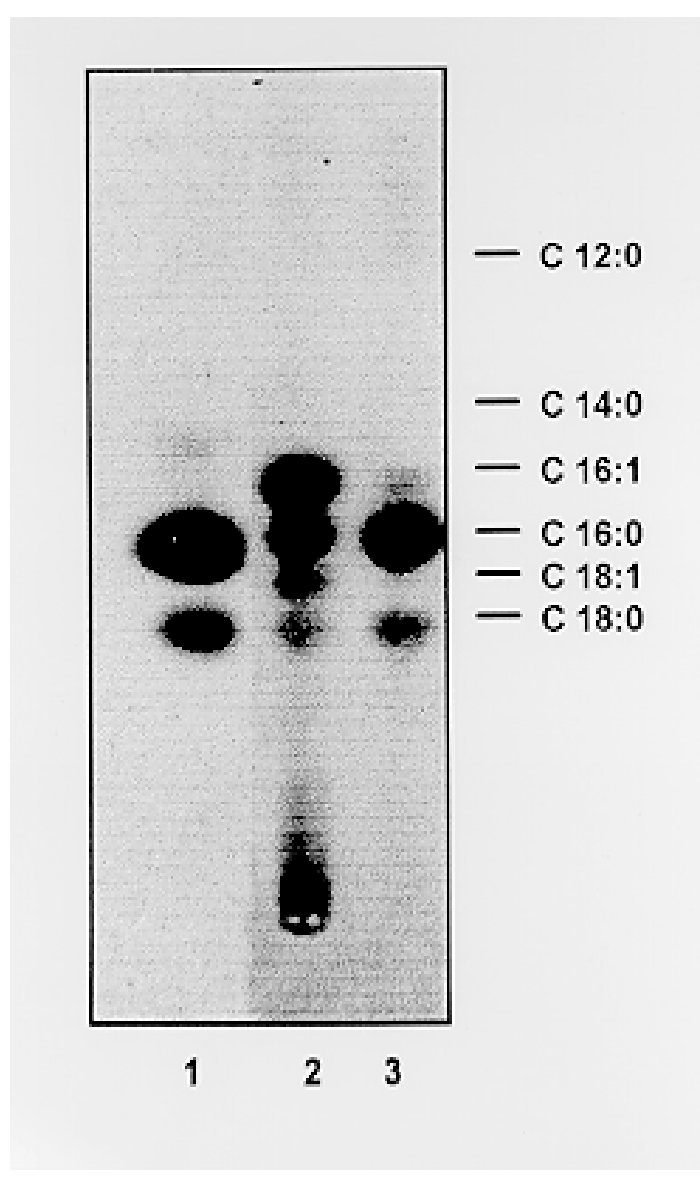

Fig. 4: analysis of free fatty acids as their methyl ester derivatives by reverse-phase thin layer chromatography in acetonitrile:acetic acid (1:1). Lane 1: free fatty acids from trypomastigote forms; lane 2: free fatty acids from Fig. 1a (lane 2); lane 3: samples from lane 2 subjected to hydrogenation. The position of standard fatty acids is shown on the right. The nature of the material retained at the origin of lane 2 was no further analyzed.

they were not found when labeling with $\left[{ }^{3} \mathrm{H}\right]-$ palmitic acid, as shown in Fig. 4, lane 1.

A well characterized phenomenon associated with the acclimation of organisms to changes is the regulation of the molecular motion or "fluidity" of membrane lipids via unsaturation of the fatty acids. This phenomenon depends on the activation of desaturases activities (Vigh et al. 1993) and may become appreciable and critical for the shedding of certain antigens. It must be stressed also that the fatty acids from trypomastigote GPIs are mostly unsaturated (Ferguson 1997) and, at least in part, could have been released by activated acyl hydrolases.

Further investigation will be necessary to elucidate whether desaturation in fact occurs during or after shedding as well as the degree of contribu- tion of GPI-anchor bound unsaturated fatty acids to the pool of shed lipids.

\section{REFERENCES}

Abuin G, Couto AS, Lederkremer RM, Casal OL, Galli C, Colli W, Alves MJM 1996. Trypanosoma cruzi: The Tc-85 surface glycoprotein shed by trypomastigotes bears a modified glycosylphosphatidylinositol anchor. Exp Parasitol 82: 290-297.

Acosta-Serrano A, Schenkman S, Yoshida N, Mehlert A, Richardson JM, Ferguson MAJ 1995. The lipid structure of the glycosylphosphatidylinositol-anchored mucin-like sialic acid acceptors of Trypanosoma cruzi changes during parasite differentiation from epimastigotes to infective metacyclic trypomastigote forms. J Biol Chem 270: 2724427253.

Affranchino JL, Ibañez CF, Luquetti AO, Rassi A, Reyes MB, Macina RA, Åslund L, Pettersson U, Frasch ACC 1989. Identification of a Trypanosoma cruzi antigen that is shed during the acute phase of Chagas disease. Mol Biochem Parasitol 34: 221-228.

Agusti R, Couto AS, Campetella OE, Frasch ACC, Lederkremer RM 1997. The trans-sialidase of Trypanosoma cruzi is anchored by two different lipids. Glycobiology 7: 731-735.

Almeida IC, Ferguson MAJ, Schenkman S, Travassos LR 1994. Lytic anti-a-galactosyl antibodies from patients with chronic Chagas disease recognize novel O-linked oligosaccharides on mucin-like glycosylphosphatidylinositol-anchored glycoproteins of Trypanosoma cruzi. Biochem J 304: 793802.

Andrews NW, Colli W 1982. Adhesion and interiorization of Trypanosoma cruzi in mammalian cells. J Protozool 29: 264-269.

Araujo FG 1982. Detection of circulating antigens of Trypanosoma cruzi by enzyme immunoassay. Ann Trop Med Parasitol 76: 25-36.

Bertello LE, Andrews NW, Ledrekremer RM 1996. Developmentally regulated expression of ceramide in Trypanosoma cruzi. Mol Biochem Parasitol 79: 143151.

Corral RS, Altcheh J, Alexandre SR, Grinstein S, Freilij H, Katzin AM 1996. Detection and characterization of antigens in urine of patients with acute, congenital and chronic Chagas' disease. J Clin Microbiol 34: 1957-1962.

Couto AS, Zingales B, Lederkremer RM, Colli W 1985. Trypanosoma cruzi: metabolic labeling of trypomastigote sialoglycolipids. Experientia 41:736738.

Couto AS, Uhrig ML, Agusti R, Befumo MF, Zingales B, Colli W, Lederkremer RM 1991. Trypanosoma cruzi: Incorporation of $\left[{ }^{3} \mathrm{H}\right]$-palmitic acid and $\left[{ }^{3} \mathrm{H}\right]-$ galactose into components shed by trypomastigotes. Biochem Int 24: 991-1002.

Couto AS, Lederkremer RM, Colli W, Alves MJM 1993. The glycosylphosphatidylinositol anchor of the trypomastigote-specific Tc-85 glycoprotein from Trypanosoma cruzi. Metabolic labeling and structural studies. Eur J Biochem 217: 597-602. 
Da Silveira JF, Colli W 1981. Chemical composition of the plasma membrane from epimastigote forms of Trypanosoma cruzi. Biochim Biophys Acta 644: 341-350.

DoCampo R, Pignataro OP 1991. The inositol phosphate/diacylglycerol signalling pathway in Trypanosoma cruzi. Biochem J 275: 407-411.

Dzbenski TH 1974. Exoantigens of Trypanosoma cruzi in vivo. Tropenmed Parasitol 25: 485-491.

Esteves MG, Gonzales-Perdomo M, Alviano CS, Angluster J, Goldenberg S 1989. Changes in fatty acid composition associated with differentiation of Trypanosoma cruzi. FEMS Microb Lett 59: 31-34.

Ferguson MAJ 1997. The surface glycoconjugates of trypanosomatid parasites. Phil Trans $R$ Soc Lond B 352:1295-1302.

Gonçalves MF, Umezawa ES, Katzin AM, de Souza W, Alves MJM, Zingales B, Colli W 1991. Trypanosoma cruzi: shedding of surface antigens as membrane vesicles. Exp Parasitol 72: 43-53.

Güther MLS, Cardoso de Almeida ML, Yoshida N, Ferguson MAJ 1992. Structural studies on the glycosylphosphatidylinositol membrane anchor of Trypanosoma cruzi 1G7-antigen. The structure of the glycan core. J Biol Chem 267: 6820-6828.

Kaneda Y, Nagakura K, Goutsu T 1986. Lipid composition of three morphological stages of Trypanosoma cruzi. Comp Biochem Physiol 83B: 533-536.

Kates M 1986. Techniques of lipidology, p. 1-464. In RH Burdon \& PH van Knippenberg (eds), Laboratory Techniques in Biochemistry and Molecular Biology, Elsevier, Amsterdam.

Leon W, Monteiro AM, Alviano CS, Esteves MJG, Angluster J 1989. Fatty acid composition of amastigote and trypomastigote forms of Trypanosoma cruzi. Acta Trop 46: 131-136.

Machado de Domenech EE, García M, Garrido MN, Racagni G 1992. Phospholipids of Trypanosoma cruzi: increase of polyphosphoinositides and phosphatidic acid after cholinergic stimulation. FEMS Microbiol Lett 95: 267-270.

Manku MS 1983. A comparison of GLC and HPLC methods for determining fatty acid composition of evening primrose and soybean oil. J Chromat Sci 21 : 367-369.

Menon AK 1994. Structural analysis of glycosylphosphatidylinositol anchors. Meth Enzymol 230: 418-442.

Petry K, Eisen H 1989. Chagas disease: a model for the study of autoimmune diseases. Parasitol Today 5: 111-116.
Petry K, van Voorhis WC 1991. Antigens of Trypanosoma cruzi that mimic mammalian nervous tissues: investigations of their role in the autoimmune pathophysiology of chronic Chagas disease. Res Immunol 142: 151-156.

Pollevick GD, Affranchino JL, Frasch ACC, Sánchez DO 1991. The complete sequence of a shed acutephase antigen of Trypanosoma cruzi. Mol Biochem Parasitol 47: 247-250.

Racagni G, Lema MG, Hernandez G, MachadoDomenech EE 1995. Fetal bovine serum induces changes in fatty acid composition of Trypanosoma cruzi phosphoinositides. Canad J Microbiol 41: 951954.

Schneider P, Schnur LF, Jaffe CL, Ferguson MAJ, McConville MJ 1994. Glycoinositol-phospholipid profiles of four serotypically distinct Old World Leishmania strains. Biochem J 304: 603-609.

Singh JK, Dasgupta A, Adayev T, Shahmehdi SA, Hammond D, Banerjee P 1996. Apoptosis is associated with an increase in saturated fatty acid containing phospholipids in the neuronal cell line, HN2-5. Biochim Biophys Acta 1304: 171-178.

Uhrig ML, Couto AS, Lederkremer RM, Zingales B, Colli W 1992. Metabolic labelling and partial characterisation of a sulfoglycolipid in Trypanosoma cruzi trypomastigotes. Carbohydr Res 231: 329-334.

Uhrig ML, Couto AS, Colli W, Lederkremer RM 1996. Characterization of inositolphospholipids in Trypanosoma cruzi trypomastigote forms. Biochim Biophys Acta 1300: 233-239.

Uhrig ML, Couto AS, Alves MJM, Colli W, Lederkremer RM 1997. Trypanosoma cruzi: Nitrogenous-base containing phosphatides in trypomastigote forms. Isolation and chemical analysis. Exp Parasitol 87: 8-19.

Vance DE 1990. Phosphatidylcholine metabolism: masochistic enzymology, metabolic regulation, and lipoprotein assembly. Biochem Cell Biol 68: 1151-1165.

Vigh L, Los DA, Horváth I, Murata N 1993. The primary signal in the biological perception of temperature: Pd-catalyzed hydrogenation of membrane lipids stimulated the expression of the desA gene in Synechocystis PCC6803. Proc Natl Acad Sci USA 90: 9090-9094.

Whitlow M, Iida K, Marshall P, Silber R, Nussenzweig V 1993. Cells lacking glycan phosphatidylinositollinked proteins have impaired ability to vesiculate. Blood 81: 510-516. 